\title{
Synthesis, structure, and evaluation of a $\beta$-cyclodextrin-artificial carbohydrate conjugate for use as a doxorubicin-carrying molecule
}

Takashi Yamanoi ${ }^{\text {a,*}}{ }^{*}$ Yoshiki Oda ${ }^{b}$, Kaname Katsurayac, Toshiyuki Inazud, and Kenjiro Hattori ${ }^{\mathrm{e}}$

${ }^{a}$ Faculty of Pharmaceutical Sciences, Josai University, 1-1 Keyakidai, Sakado, Saitama 350-0295, Japan

${ }^{b}$ Technology Joint Management Office, Tokai University, 4-1-1 Kitakaname, Hiratsuka, Kanagawa 259-1292, Japan

${ }^{c}$ Department of Human Ecology, Wayo Women's University, Chiba 272-8533, Japan

${ }^{d}$ Department of Applied Chemistry, School of Engineering, and Institute of Glycotechnology, Tokai University, Kanagawa 259-1292, Japan

${ }^{e}$ R\&D Lab, NanoDex Inc., 2-3227 Mita, Kawasaki, Kanagawa 214-0034, Japan

\begin{abstract}
This paper describes the synthesis of a $\beta$-cyclodextrin $(\beta-C y D)$ derivative conjugated with a C,C-glucopyranoside containing a benzene unit. Its doxorubicin-inclusion ability and structure are also discussed. SPR analysis revealed that the $\beta$-CyD conjugate had a high inclusion association value of $3.8 \times 10^{6} \mathrm{M}^{-1}$ for immobilized doxorubicin. NMR structural analysis suggested that its high doxorubicin-inclusion ability was due to the formation of the inclusion complex as a result of the $\pi-\pi$ stacking interaction between the benzene ring of the conjugate and the A ring of doxorubicin.
\end{abstract}

\section{Introduction}

Cyclodextrin (CyD) derivatives conjugated with sugar moieties have both the drug-inclusion ability of CyDs and the cell-recognition ability of sugar moieties. As a result, they are expected to carry drug molecules to targeted cells. Control of the drug-inclusion and release abilities of CyDs is of great importance in the development of drug-carrying molecules containing CyD. ${ }^{1}$

We recently synthesized several $\beta$-CyDs conjugated with a sugar moiety. ${ }^{2}$ These $\beta$-CyD conjugates were characterized by the benzene ring unit present in the spacer between the sugar moiety and the $\beta$-CyD unit. We revealed some inclusion properties and specific structures of the CyD-sugar conjugates. SPR assays indicated that they had remarkably high inclusion association constants $\left(\mathrm{K}_{\mathrm{a}}=10^{5}-10^{6} \mathrm{M}^{-1}\right.$ level $)$ for immobilized doxorubicin (Dox, anticancer agent). These $K_{a}$ values were 100-1000 times higher than those of ordinary $\beta$-CyD. We then attempted to elucidate their excellent Dox-inclusion abilities through NMR structural analyses, which suggested that the benzene unit in the $\beta$-CyD conjugates formed specific conformations, as shown in Figure 1. The NMR spectra of CyD conjugates only (without Dox) indicated that they had a "closed can structure," where the primary side of $\beta$-CyD was capped by the benzene unit. This conformation of the benzene unit increased the hydrophobicity of the CyD cavity and promoted the inclusion of Dox into the cavity. Conversely, the NMR spectra of both the $\beta$-CyD conjugates and Dox indicated that they had an "open can structure," where the benzene unit was parallel to the CyD cavity. This specific conformation of the benzene unit caused a $\pi-\pi$ stacking interaction between the 
benzene unit of the CyD conjugate and the A ring of Dox, as well as strengthened the Dox inclusion complexation. ${ }^{3}$ Thus, the benzene unit of the $\beta$-CyD conjugates has serious influence on Dox inclusion.

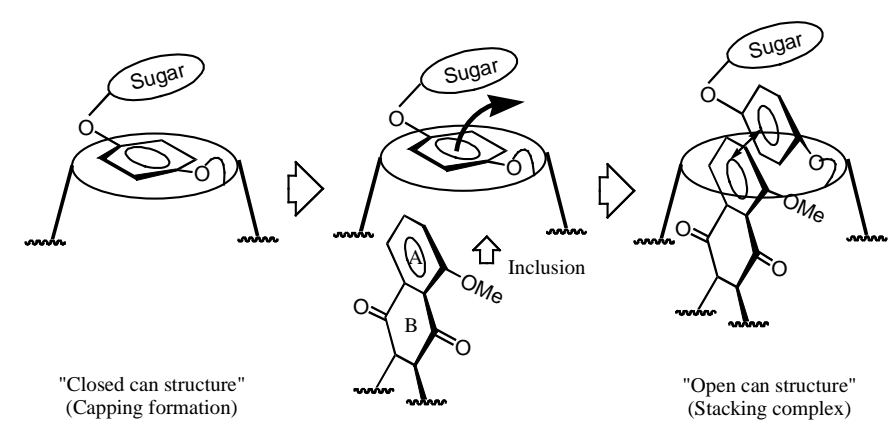

Figure 1. Specific conformations of the benzene ring of our prepared sugar- $\beta$-CyD conjugates.

In addition, SPR assays revealed that the sugar moieties of the $\beta$-CyD conjugates bound to the sugar-binding proteins (lectins) with appropriate binding affinities. Therefore, these $\beta$-CyD conjugates are promising Dox-carrying molecules.

Our studies on glycosidation reactions enabled successful development of a synthetic method for preparing C,C-glycopyranosides, which are expected to become a new type of artificial sugar. ${ }^{4}$ We then decided to design a new Dox-carrying molecule using a C,C-glycopyranoside. Figure 2 shows our newly designed $\beta$-CyD derivative conjugated with a C,C-glucopyranoside (1). $\beta$-CyD conjugate $\mathbf{1}$ is structurally unique in that the benzene unit is at the end of the spacer, placing the artificial sugar moiety between the benzene unit and the $\beta$-CyD unit. We predicted that this structure would make the spacer more flexible, enabling easy formation of the "closed can structure," which could smoothly convert to the "open can structure” upon incorporation of Dox. We were also interested in the binding of the artificial sugar moiety to lectin (Concanavalin A, Con A).

This paper describes the synthesis and evaluation of $\mathbf{1}$ as a Dox-carrying molecule. The Dox-inclusion ability and the lectin binding affinity of $\mathbf{1}$ were investigated through SPR assays. The behavior of the benzene unit of $\mathbf{1}$ was elucidated through NMR spectral analysis.

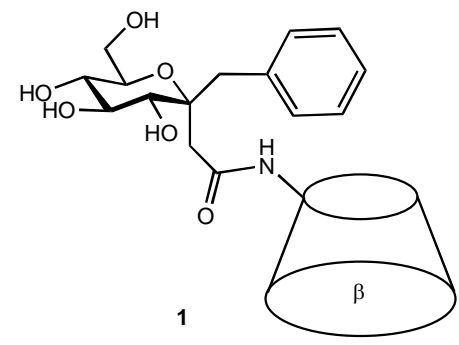

Figure 2. Newly designed $\beta$-CyD conjugate $\mathbf{1}$. 


\section{Results and discussion}

\subsection{Synthesis of $\beta$-CyD conjugate 1}

Scheme 1 shows the synthetic procedure for the formation of $\mathbf{1}$ from 1- $\alpha$-allyl-1- $\beta$-benzyl-1-deoxy-D-glucopyranoside $(2)^{4}$ and mono-6-amino-6-deoxy- $\beta$-CyD. Ozonization of 2 at $-78{ }^{\circ} \mathrm{C}$ followed by reduction with triphenylphosphine gave aldehyde 3 . Subsequent oxidation of 3 using $\mathrm{NaClO}_{2}$ and $\mathrm{NaH}_{2} \mathrm{PO}_{4}$ in the presence of 2-methyl-2-butene afforded the corresponding carboxylic acid (4). The coupling reaction of 4 with mono-6-amino-6-deoxy- $\beta-C y D$ using dimethylphosphinothioyl chloride and diisopropylethylamine (DIEA) in DMF afforded 1.

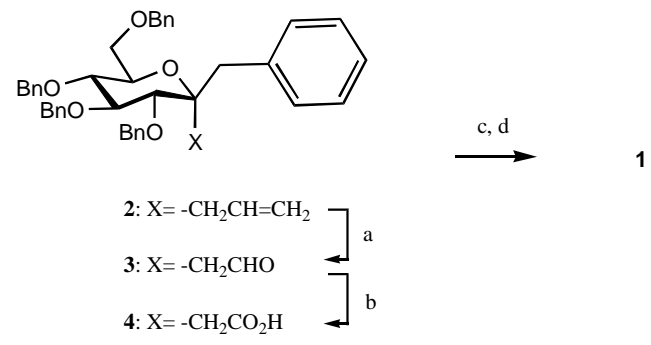

Scheme 1. Preparation of 1: (a) $-78{ }^{\circ} \mathrm{C}, \mathrm{O}_{3}, \mathrm{CH}_{2} \mathrm{Cl}_{2}, 10$ min, then $\mathrm{Ph}_{3} \mathrm{P},-78{ }^{\circ} \mathrm{C} \rightarrow \mathrm{RT}, 2 \mathrm{~h}, 97 \%$; (b) $\mathrm{NaClO}_{2}$, $\mathrm{NaH}_{2} \mathrm{PO}_{4}$, 2-methyl-2-butene, $t$-BuOH- $\mathrm{H}_{2} \mathrm{O}, 24 \mathrm{~h}, 96 \%$; (c) $\mathrm{Me}_{2} \mathrm{P}(\mathrm{S}) \mathrm{Cl}$, DIEA, DMF, 40 min, then mono-6-amino-6-deoxy- $\beta$-CyD, 24 h; (d) $\mathrm{Pd}(\mathrm{OH})_{2}, \mathrm{H}_{2}$, DMF, 58\%.

\subsection{Evaluation of 1 through SPR assays}

\subsubsection{Dox-inclusion ability of $\mathbf{1}$}

Dox was immobilized on the sensor cuvette of the SPR optical biosensor and measurement using 1 was conducted under the same conditions as previously reported. ${ }^{5}$ The amount of immobilized Dox was $0.167 \mathrm{ng} / \mathrm{mm}^{2}$. Figure 3 shows the kinetic linear plot of $\mathbf{1}$. The association rate constant $\left(\mathrm{k}_{\mathrm{a}}\right)$ and dissociation rate constant $\left(\mathrm{k}_{\mathrm{d}}\right)$ of $\mathbf{1}$ for immobilized Dox were $2.4 \times 10^{4} \mathrm{M}^{-1} \mathrm{~s}^{-1}$ and $6.4 \times 10^{-3} \mathrm{~s}^{-1}$, respectively, and the inclusion association $\left(\mathrm{K}_{\mathrm{a}}\right)$, calculated by the relation of $\mathrm{K}_{\mathrm{a}}=\mathrm{k}_{\mathrm{a}} / \mathrm{k}_{\mathrm{d}}$, was $3.8 \times 10^{6} \mathrm{M}^{-1}$. These values of $\mathbf{1}$ were in close agreement with those of our previously prepared sugar-conjugated $\beta$-CyD derivatives involving a benzene unit, ${ }^{6}$ whose $K_{a}$ values were generally $10^{3}$ times higher than those of ordinary $\beta$-CyD derivatives. ${ }^{7}$ Thus, we found that conjugate $\mathbf{1}$ had the excellent Dox-inclusion ability that we expected. This suggested that the benzene unit of $\mathbf{1}$ had a similar major influence on the improvement of its Dox-inclusion ability.

\subsubsection{Binding ability of $\mathbf{1}$ to immobilized Con A}

Con A was immobilized on the sensor cuvette of the SPR optical biosensor and measurement using 1 was conducted under the same conditions as previously reported. ${ }^{5}$ The amount of immobilized Con A was $2.52 \mathrm{ng} / \mathrm{mm}^{2}$. Figure 4 shows the kinetic linear plot of $\mathbf{1}$. The $k_{a}, k_{d}$, and $K_{a}$ of $\mathbf{1}$ for immobilized Con A were $8.0 \times 10^{2} \mathrm{M}^{-1} \mathrm{~s}^{-1}$, $2.7 \times 10^{-3} \mathrm{~s}^{-1}$, and $3.0 \times 10^{5} \mathrm{M}^{-1}$, respectively. The reported $\mathrm{K}_{\mathrm{a}}$ value of PNP $\alpha$-D-mannopyranoside for Con A is 
$2.0 \times 10^{5} \mathrm{M}^{-1}$, hence the $\mathrm{K}_{\mathrm{a}}$ value of $\mathbf{1}$ is in close agreement. ${ }^{8}$ Thus, we found that the C,C-glucopyranoside moiety of $\mathbf{1}$ was recognized by Con A.

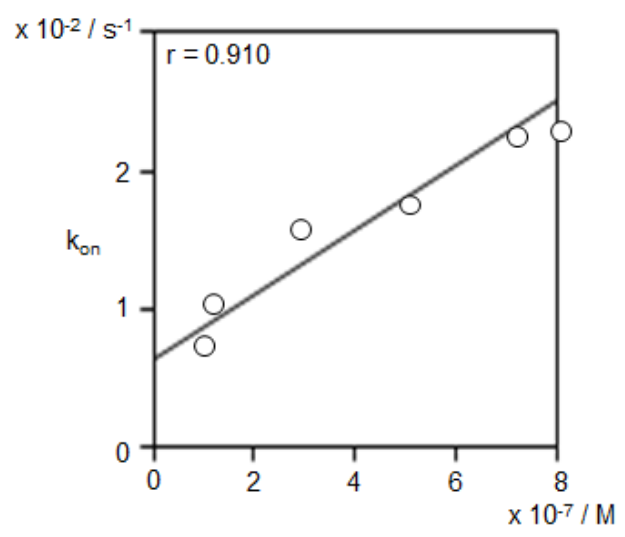

Figure 3. Kinetic linear plot of 1 for immobilized Dox.

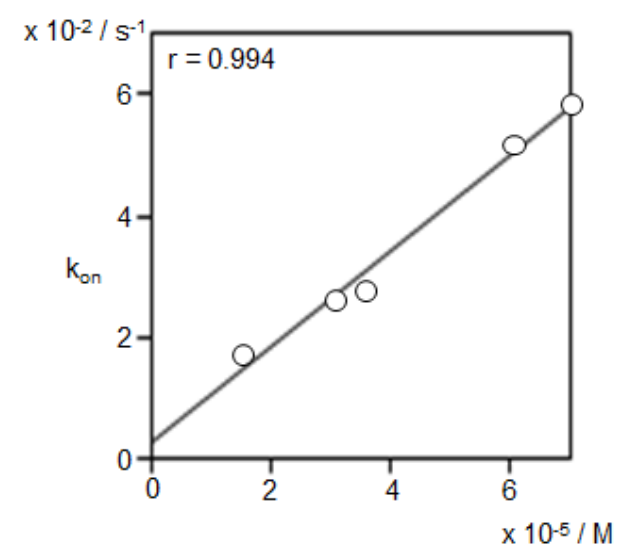

Figure 4. Kinetic linear plot of 1 for immobilized Con A.

\subsection{Structures of $\mathbf{1}$ and the 1-Dox inclusion complex}

\subsection{1. ${ }^{1} H$ NMR assignment of 1 and the 1 -Dox inclusion complex}

Figure 5 indicates the ${ }^{1} \mathrm{H}$ NMR spectra of $\mathbf{1}$, Dox, and the mixed sample of $\mathbf{1}$ and DXR (1:1) in $\mathrm{D}_{2} \mathrm{O}$ at $25{ }^{\circ} \mathrm{C}$. Assignment of the ${ }^{1} \mathrm{H}$ NMR chemical shifts was determined by one- and two-dimensional NMR spectroscopic techniques, including ${ }^{1} \mathrm{H}-{ }^{1} \mathrm{H}$ COSY, HSQC, HOHAHA, and HMBC (data not shown). Table 1 lists these assignments.

\subsubsection{Structure of conjugate 1}

In Figure 5, the ${ }^{1} \mathrm{H}$ NMR spectrum of $\mathbf{1}$ shows that the peaks for the $\mathrm{Ha}, \mathrm{Hb}$, and Hc protons of the benzene ring (identified in Figure 5 (iv)) are broad. This suggests that the benzene ring is influenced by CyD. 
Figure 6 presents the ROESY spectrum of $\mathbf{1}$ in $\mathrm{D}_{2} \mathrm{O}$ at $25^{\circ} \mathrm{C}$. Some long-range ROE interactions were observed. The Hb proton of the benzene ring had four ROE signals (a) with H6 protons (3.63, 3.71, 3.81, and 3.89 ppm) of CyD with similar intensities. ${ }^{1} \mathrm{H}-{ }^{1} \mathrm{H}$ COSY revealed that these four $\mathrm{H} 6$ protons bound with $\mathrm{C} 6$ carbons of three different glucoses of CyD. Considering the observations together with the molecular sizes of the benzene ring and $\beta-\mathrm{CyD}$, it is inevitable that both of the two Hb protons of the benzene ring are involved in the ROEs. The Hc proton of the benzene ring also had an ROE interaction (c) with H6 of CyD. It was thus confirmed that three protons (two $\mathrm{Hb}$ protons and one Hc proton) of the flat benzene ring exist near the H6 protons of CyD. This means that the benzene ring lies over the primary side of $\mathrm{CyD}$. In other words, the primary side of CyD is capped by the benzene ring and $\mathbf{1}$ forms the "closed can structure" as shown in Figure 7 [A]. In addition, two ROE signals (b and d) were observed. The signals indicate that one $\mathrm{Hb}$ proton and one Hc proton of the benzene ring simultaneously exist near $\mathrm{H} 5$ of CyD. It suggests the plane of the benzene ring inclines to the horizontal face of CyD.

The ROE signal (e) between the Hc proton of the benzene ring and the Ha proton at C9' was observed. This means that the plane of the benzene ring exists nearly parallel to the C9'-Ha9' axis and the coplanar conformation is formed. ${ }^{9}$ The ROE signal (f) between the Hb proton at C9' and the H4' proton was observed. These observations show that the structure of the unit from the sugar moiety to the benzene ring is conformationally fixed. In addition, both the Ha9' and the Hb9' had the ROE interactions ( $g$ and h) with the same H6 proton (3.76 ppm) of CyD. This observation determined how the unit from the sugar moiety to the benzene ring exists above CyD. It is also the evidence that the benzene ring lies over the primary side of CyD.

The molecular structure of $\mathbf{1}$ suggested by all the above-mentioned ROEs can be summarized as follows: the primary side of CyD is capped by the benzene ring and the "closed can structure" is formed as shown in Figure 7 [A]. The sugar moiety is located above the benzene ring. The tilt of the benzene ring is estimated to be about 30 degrees to the horizontal face of CyD.

\subsubsection{Structure of the 1-Dox inclusion complex}

Several reports revealed that Dox formed the inclusion complex with $\beta$-CyD only in a $1: 1$ stoichiometry and the A ring of Dox was included through the secondary side of $\beta$-CyD (A-up orientation). ${ }^{10}$ We also used the mixed sample of 1 and Dox (1:1) in the following NMR experiments.

Figure 5 shows the ${ }^{1} \mathrm{H}$ NMR spectrum of the mixed sample in $\mathrm{D}_{2} \mathrm{O}$ at $25{ }^{\circ} \mathrm{C}$. Shifting and broadening of some signals were observed. The protons ( $\mathrm{H} 4$ and H14) on the D ring in Dox shifted significantly downfield 0.23-0.25. The protons (Ha3, Hb3, Ha13, and Hb13) on the D ring shifted upfield 0.02-0.07 ppm. The protons (He and $\mathrm{Hd}$ ) on the A ring in Dox shifted upfield 0.02-0.07 ppm, accompanied by broadening. The proton signals (Ha and $\mathrm{Hb}$ ) on the benzene ring of $\mathbf{1}$ also moved upfield $0.03-0.04 \mathrm{ppm}$. These upfield shifts support the parallel stacking configuration between the benzene ring of $\mathbf{1}$ and the benzene unit of Dox.

Figure 9 shows the NOESY spectrum of the mixed sample. Several long-range NOE interactions were observed. The He proton on the A ring in Dox had an NOE interaction (i) with H6 of CyD. The NOE interactions ( $\mathrm{j}$ and $\mathrm{m}$ ) between the H5” proton and the H3 proton were observed, while the NOESY spectrum of only Dox indicated the NOE interaction between the H1" proton and the H3 proton (data not shown). These observations mean that the inclusion of Dox into 1 rotated the glycoside bond of the amino sugar of Dox. The significant downshift of the H14 
proton of Dox mentioned above would be caused by the conformation change of Dox influenced by the amino sugar. These NOE observations ( $\mathrm{i}, \mathrm{j}$ and $\mathrm{m}$ ) tell that Dox forms an inclusion complex with $\mathbf{1}$ with A-up orientation and the A ring of Dox exists close to H6 of CyD.

The $\mathrm{Hb}$ proton of the benzene ring of $\mathbf{1}$ had two NOE interactions (a) with $\mathrm{H} 6$ of CyD; one showed a strong signal intensity, and the other showed a weak signal intensity. This Hb proton had an NOE interaction (b) with H5 of CyD with a strong signal intensity, too. A quite similar signal tendency was observed in the NOE interactions (c and d) between the Hc proton of the benzene ring and $\mathrm{H} 6$ or $\mathrm{H} 5$ of CyD. Considering the existence of the A ring of Dox near H6 of CyD, the "closed can structure" disappeared upon inclusion of Dox. It was strongly suggested that one $\mathrm{Hb}$ proton and one Hc proton of the benzene ring were concerned with the above NOE interactions (a, b, c and d).

The Hc proton of the benzene ring of $\mathbf{1}$ had strong NOE interactions (e and f) with both the Ha and Hb protons on 9' of $\mathbf{1}$ with similar intensities. The weak NOE interactions ( $\mathrm{k}$ and l) between the Hb proton of the benzene ring and those on 9' of $\mathbf{1}$ were observed with similar intensities. These observations suggest that the plane of the benzene ring of 1 exists nearly parallel to the C3'-C9' axis, based on the formation of a stable coplanar conformation. ${ }^{9}$ Therefore, the C9'-C10' axis of $\mathbf{1}$ rotates by 60 degrees upon Dox inclusion. The proton on 4' of 1 had NOE interactions ( $\mathrm{g}$ and $\mathrm{h}$ ) with both the $\mathrm{Ha}$ and $\mathrm{Hb}$ protons on 9' with similar signal intensities. This observation shows that the C3'-C9' axis of 1 rotates by 120 degrees upon Dox inclusion. In addition, both the Ha9' and the Hb9' had the NOE interactions (expansion data not shown) with the same H6 proton of CyD. It means that C9' is the center of the 120 degrees rotation.

The change from the "closed can structure" to the "open can structure" of $\mathbf{1}$ can be explained logically by the above-mentioned rotations. In order to discuss stepwise the rotations of the C9'-C10' axis and the C3'-C9' axis, Newman projections are shown in Figure 8. Figure 8 [A-1] and [A-2] showed the Newman projections viewed along the C3'-C9' axis or the C9'-C10' axis of the structure Figure 7 [A] of 1, respectively. The 60 degrees rotation of the C9'-C10' axis of [A-1] makes the benzene ring vertical, as shown in [A'-1]. The following 120 degrees rotation of the C3'-C9' axis of the structure [A'-1], keeping the benzene ring vertical, moves it aside in the CyD cavity, and also moves the sugar unit away from the position above the CyD cavity, as shown in [B-1] and [B-2]. Thus, these rotations make the space which is necessary to include the Dox molecule and to stack the two aromatic rings parallel to each other ( $\pi-\pi$ parallel stacking) in the CyD cavity. Recently, Swiech et al., reported the Dox- $\beta$-CyD complexes suggesting high possibility of strong $\pi-\pi$ parallel stacking interactions between the A ring of Dox and the aromatic phenyl rings in the side chains of $\beta$-CyD based on molecular modeling. ${ }^{11}$ Their reports also support our proposed "open can structure”. 
Table 1. ${ }^{1} \mathrm{H}$ NMR chemical shifts of $\mathbf{1}$, Dox, and a mixed sample of $\mathbf{1}$ and Dox (1:1)

\begin{tabular}{|c|c|c|c|c|c|}
\hline \multirow{2}{*}{\multicolumn{2}{|c|}{ Compound }} & \multirow[b]{2}{*}{ Proton } & \multicolumn{2}{|c|}{ Chemical shift } & \multirow{2}{*}{$\begin{array}{l}\text { Chemical shift } \\
\text { change } \\
\text { Upfield }(+) / p p m \\
\text { Downfield (-)/ppm }\end{array}$} \\
\hline & & & $\begin{array}{l}\text { Single substance sample } \\
\text { (1 or Dox) }\end{array}$ & $\begin{array}{l}\text { Mixed sample } \\
\text { (1 and Dox) }\end{array}$ & \\
\hline \multirow[t]{2}{*}{1} & CyD unit & $\begin{array}{l}\text { H1 } \\
\text { H2 } \\
\text { H3 } \\
\text { H4 } \\
\text { H5 } \\
\text { H6 }\end{array}$ & 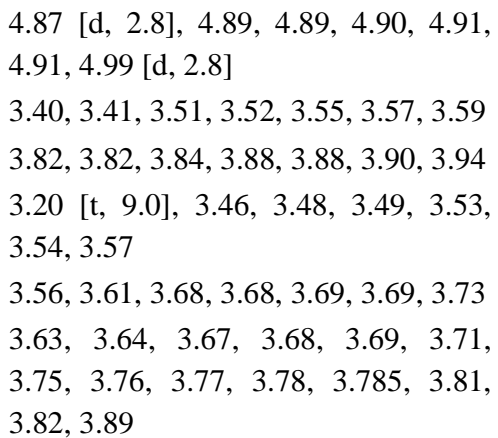 & $\begin{array}{l}4.88[\mathrm{~d}, 3.5], 4.89,4.89,4.90,4.91 \text {, } \\
4.91,4.94 \\
3.40,3.41,3.50,3.51,3.51,3.55,3.55 \\
3.78,3.78,3.82,3.82,3.84,3.88,3.90 \\
3.21[\mathrm{t}, 9.0], 3.44,3.44,3.46,3.48, \\
3.48,3.49 \\
\begin{array}{l}3.56,3.65,3.67,3.68,3.69,3.70,3.71 \\
3.59-3.61,3.73-3.76,3.76-3.81\end{array}\end{array}$ & \\
\hline & $\begin{array}{l}\text { C,C-Glucosyl } \\
\text { unit }\end{array}$ & $\begin{array}{l}\text { Ha2' } \\
\text { Hb2' } \\
\text { H4’ } \\
\text { H5’ } \\
\text { H6’ } \\
\text { H7’ } \\
\text { Ha8' } \\
\text { Hb8' } \\
\text { Ha } \\
\text { Hb } \\
\text { Hc } \\
\text { Ha9' } \\
\text { Hb9' }\end{array}$ & $\begin{array}{l}2.54[\mathrm{~d}, 15.8] \\
2.60[\mathrm{~d}, 15.8] \\
3.08[\mathrm{~d}, 9.6] \\
3.45 \\
3.47 \\
3.76 \\
2.89[\mathrm{~m}] \\
3.02[\mathrm{~m}] \\
7.19[\mathrm{bs}] \\
7.21[\mathrm{bs}] \\
7.15[\mathrm{bs}] \\
2.95[\mathrm{~d}, 14.5] \\
2.70[\mathrm{~d}, 14.4] \\
\end{array}$ & $\begin{array}{l}2.54[\mathrm{~d}, 15.9] \\
2.62[\mathrm{~d}, 15.2] \\
3.07[\mathrm{~d}, 9.6] \\
3.42 \\
3.50 \\
3.75 \\
2.90[\mathrm{~m}] \\
3.00[\mathrm{~m}] \\
7.15[\mathrm{~m}] \\
7.18[\mathrm{t}, 6.9] \\
7.15 \\
2.93[\mathrm{~d}, 14.5] \\
2.71[\mathrm{~d}, 14.5] \\
\end{array}$ & $\begin{array}{l}-0.02 \\
+0.03 \\
-0.03 \\
\\
+0.02 \\
+0.04 \\
+0.03\end{array}$ \\
\hline \multirow[t]{2}{*}{ Dox } & $\begin{array}{l}\text { Anthracycline } \\
\text { unit }\end{array}$ & $\begin{array}{l}\mathrm{Ha} 3 \\
\mathrm{Hb} 3 \\
\mathrm{H} 4 \\
\mathrm{OCH}_{3} \\
\mathrm{Hd} \\
\mathrm{He} \\
\mathrm{Hf} \\
\mathrm{Ha} 13 \\
\mathrm{Hb} 13 \\
\mathrm{H} 14\end{array}$ & $\begin{array}{l}1.91[\mathrm{~m}] \\
2.13[\mathrm{~d}, 14.4] \\
4.74[\mathrm{~d}, 4.1] \\
3.74[\mathrm{~s}] \\
7.17[\mathrm{~d}, 7.6] \\
7.47[\mathrm{t}, 7.6] \\
7.19[\mathrm{~d}, 8.2] \\
2.45[\mathrm{~d}, 17.9] \\
2.78[\mathrm{~d}, 17.2] \\
4.70[\mathrm{~d}, 4.1]\end{array}$ & $\begin{array}{l}1.89 \\
2.09[\mathrm{~d}, 11.7] \\
4.97[\mathrm{~d}, 3.5] \\
3.73[\mathrm{~s}] \\
7.10[\mathrm{~m}] \\
7.45[\mathrm{bs}] \\
7.20 \\
2.38[\mathrm{~m}] \\
2.75[\mathrm{~m}] \\
4.95\end{array}$ & $\begin{array}{l}+0.02 \\
+0.04 \\
-0.23 \\
+0.07 \\
+0.02 \\
-0.01 \\
+0.07 \\
+0.03 \\
-0.25\end{array}$ \\
\hline & Sugar unit & $\begin{array}{l}\text { H1” } \\
\text { H2” } \\
\text { H3” } \\
\text { H4” } \\
\text { H5” } \\
\text { H6” }\end{array}$ & $\begin{array}{l}5.33[\mathrm{~s}] \\
1.88-1.89 \\
3.70[\mathrm{~m}] \\
3.60 \\
4.12[\mathrm{~m}] \\
1.19[\mathrm{~d}, 6.9]\end{array}$ & $\begin{array}{l}5.30[\mathrm{bs}] \\
1.85-1.87 \\
3.61 \\
3.61[\mathrm{~m}] \\
4.09[\mathrm{~m}] \\
1.18[\mathrm{~d}, 6.9]\end{array}$ & $\begin{array}{l}+0.03 \\
+0.02-0.03 \\
+0.09 \\
+0.03\end{array}$ \\
\hline
\end{tabular}




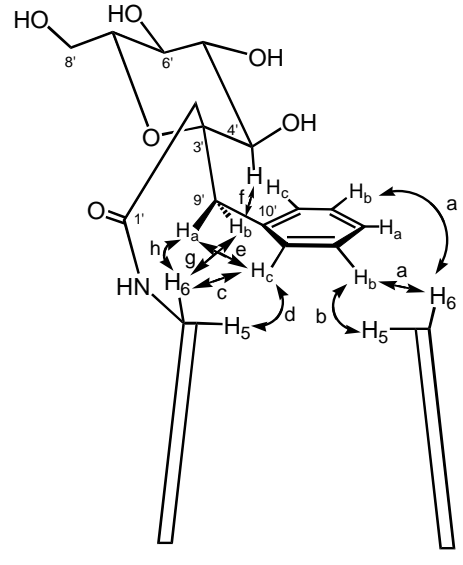

[A]
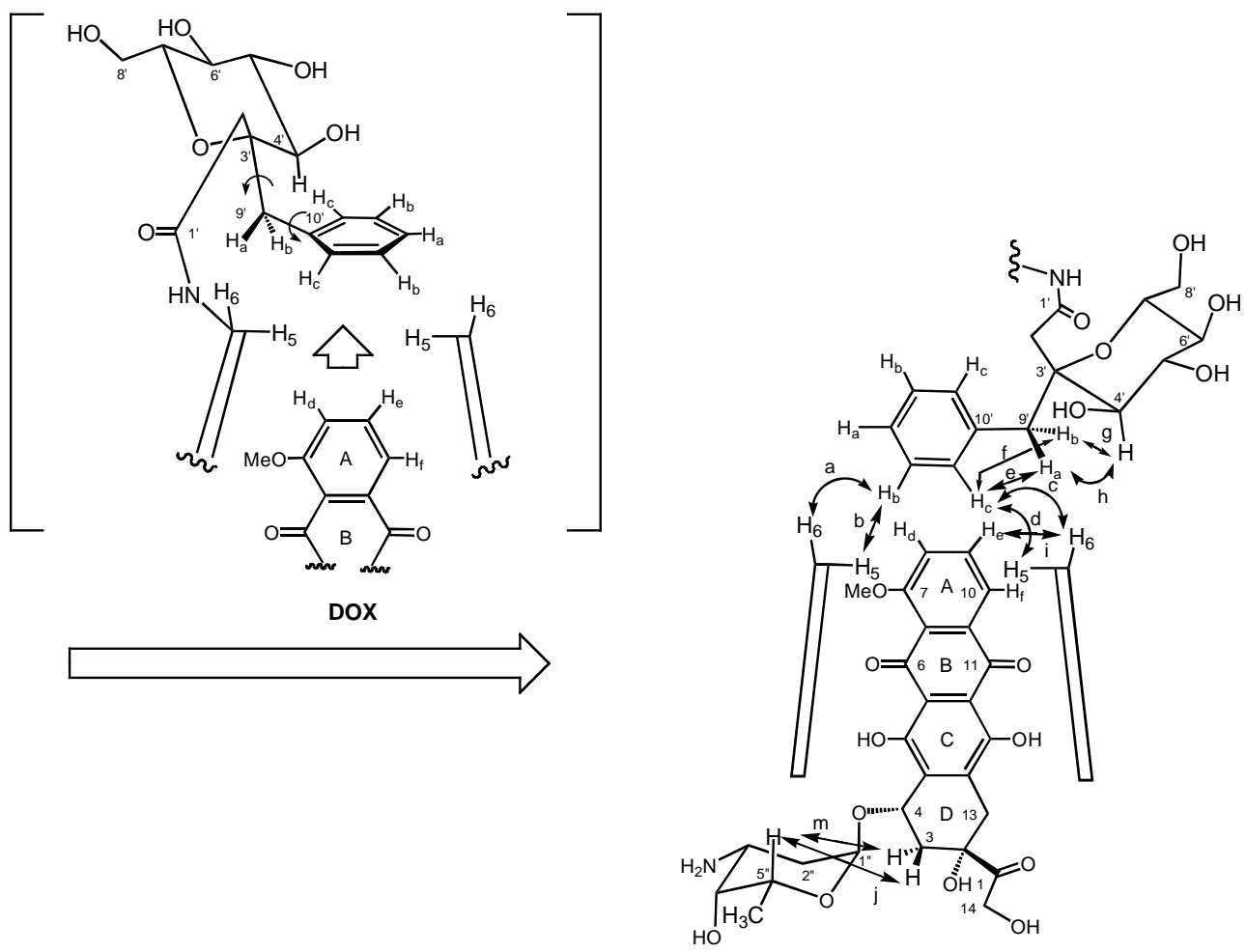

[B]

Figure 7. Postulated structures of $\mathbf{1}$ and its Dox complex. 

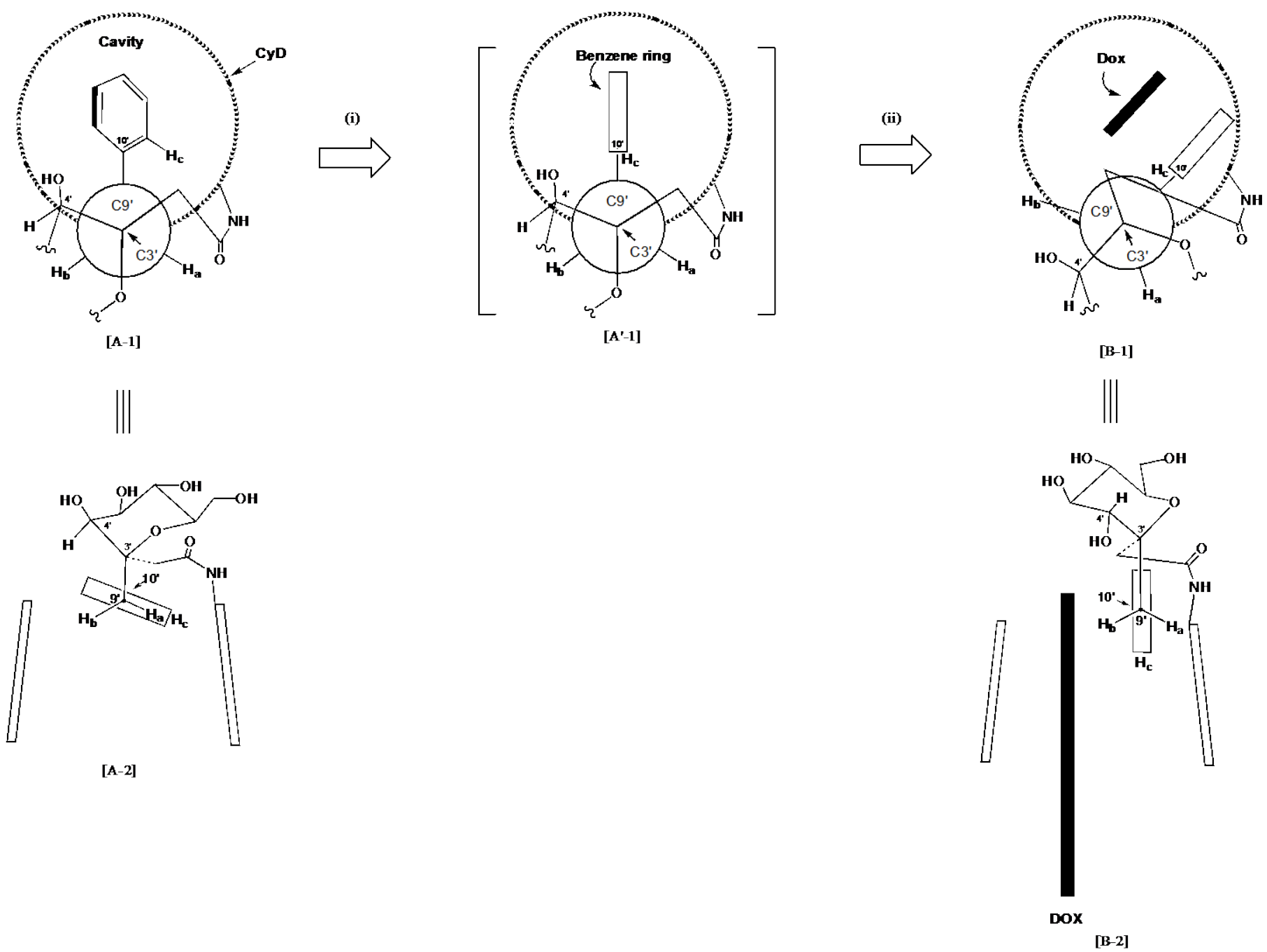

[A-2]

[B-2]

[A-1], [A'-1] and [B-1]: Newman projection viewed along the C3'- C9' axis of 1; [A-2] and [B-2]: Newman projection viewed along the C9'-C10' axis of 1. (i) 60 Degrees rotation of the C9'-C10' axis. (ii) 120 Degrees rotation of the C3'-C9' axis.

Figure 8. Newman projections. 


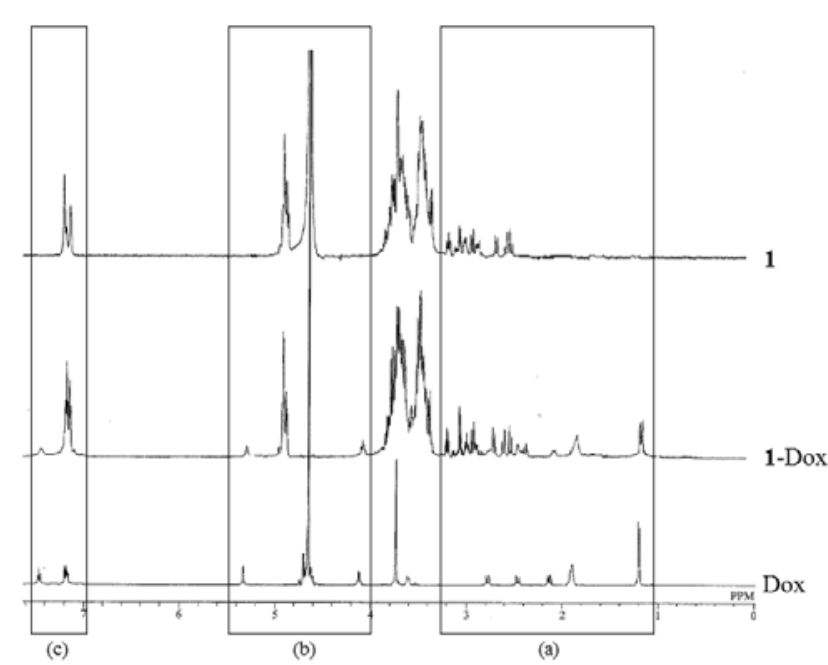

(i) ${ }^{1} \mathrm{H}$ NMR spectra

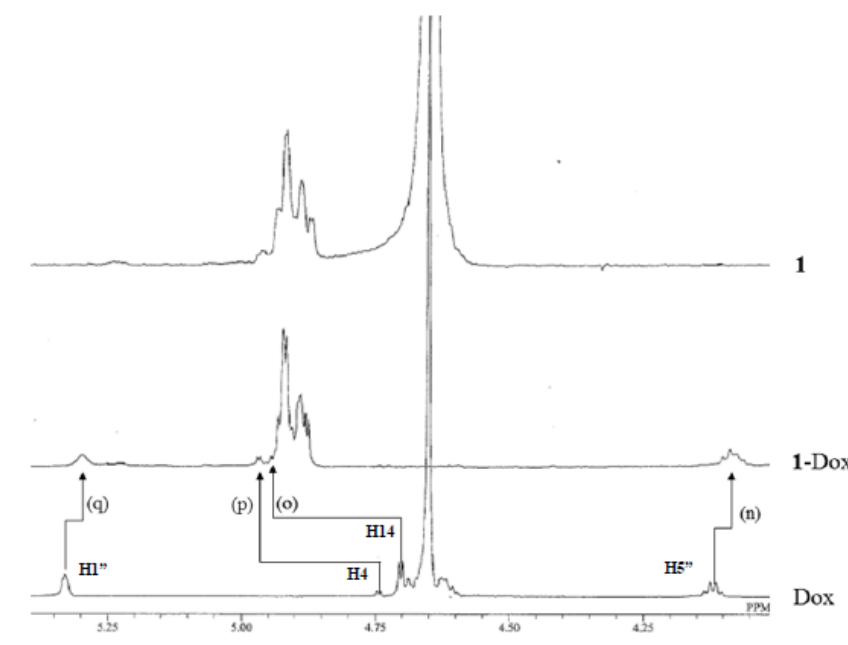

(iii) Expansion of (b)

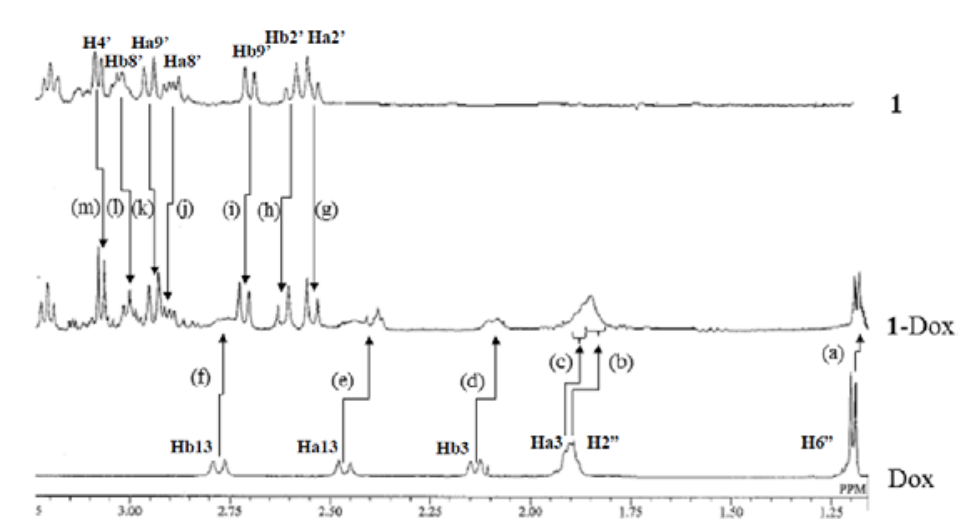

(ii) Expansion of (a)

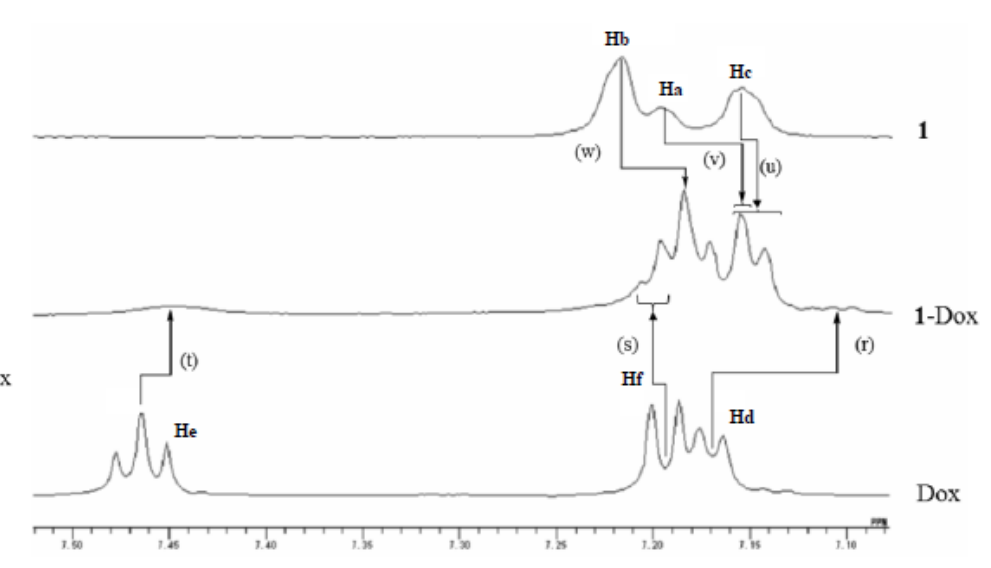

(iv) Expansion of (c)

Figure 5. ${ }^{1} \mathrm{H}$ NMR spectra of 1, Dox, and mixed 1-Dox (1:1). ( $\mathrm{D}_{2} \mathrm{O}, 25^{\circ} \mathrm{C}, 16$ scans, 1: $2 \mathrm{mM}$, Dox: $\left.2 \mathrm{mM}\right)$. 



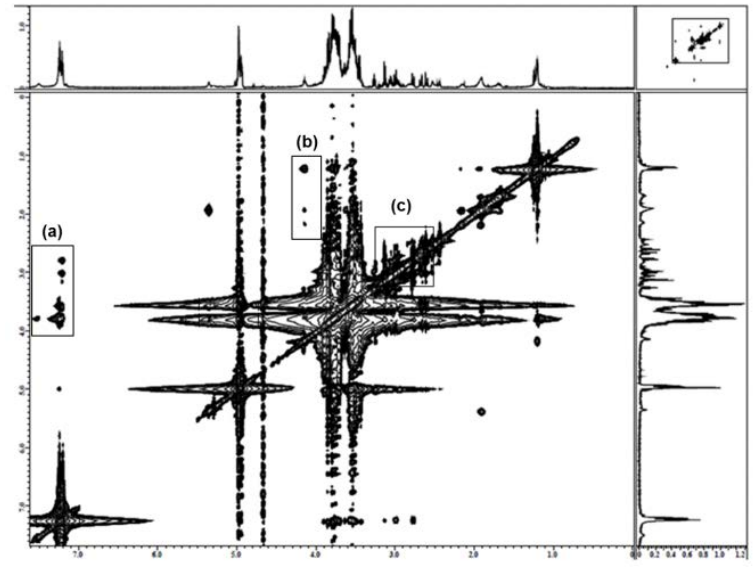

(i) NOESY NMR spectrum

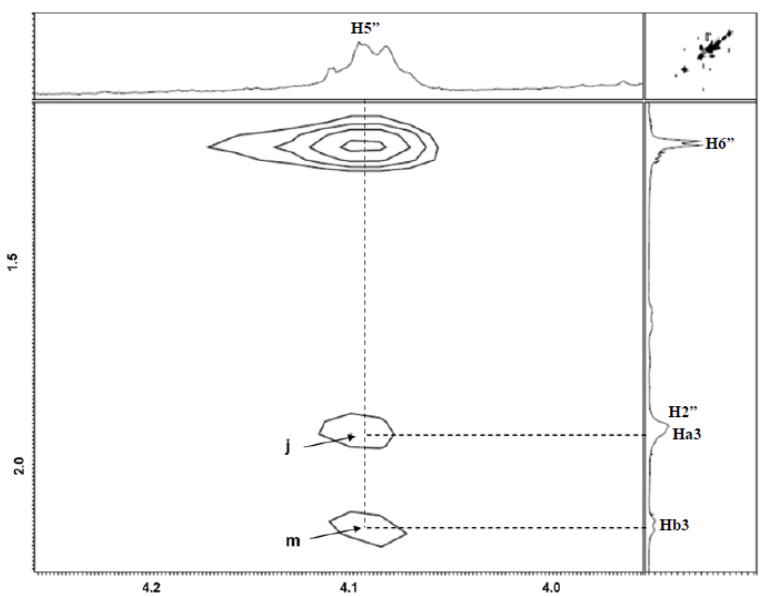

(iii) Expansion of (b)

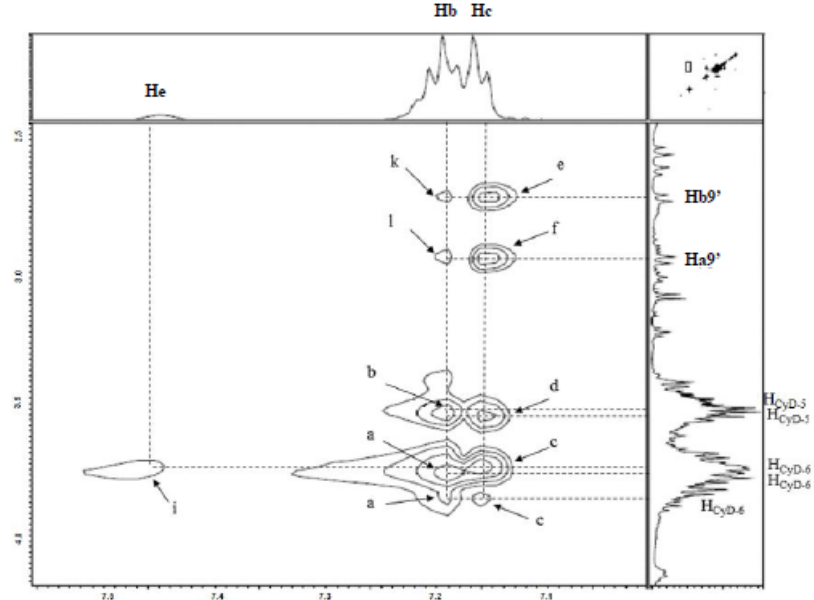

(ii) Expansion of (a)

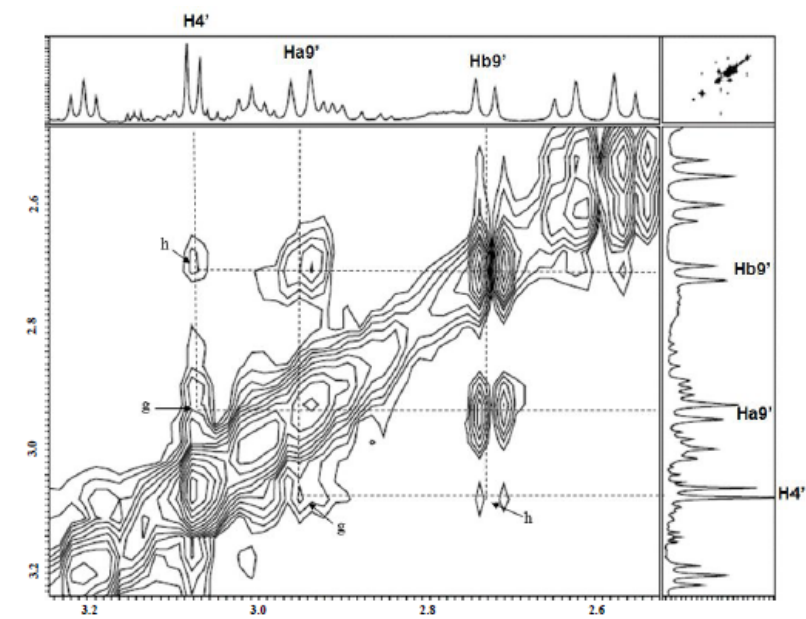

(iv) Expansion of (c)

Figure 9. NOESY NMR spectrum of mixed 1-Dox (1:1). $\left(\mathrm{D}_{2} \mathrm{O}, 25^{\circ} \mathrm{C}\right.$, mixing time: $500 \mathrm{~ms}, 64$ scans, 1: $2 \mathrm{mM}$, Dox: $2 \mathrm{mM}$ )

\section{Conclusion}

We successfully synthesized a $\beta$-CyD derivative conjugated with C,C-glucopyranoside (1). SPR analyses showed that the CyD conjugate demonstrated high Dox-inclusion ability and was able to bind to Con A with a typical inclusion association constant. NMR structural analyses revealed that the conjugate formed the "closed can structure," which converted to the "open can structure" upon incorporation of Dox. We expect this CyD conjugate to have potential use as a Dox-carrying molecule. 


\section{Experimental}

\subsection{General}

${ }^{1} \mathrm{H}$ NMR (600 MHz) and ${ }^{13} \mathrm{C}$ NMR (150 MHz) spectra were recorded on a JEOL ECA-600 spectrometer. The NOESY experiment was performed at $25{ }^{\circ} \mathrm{C}$ with a mixing time of 500 ms. The ROESY experiment was performed at $25{ }^{\circ} \mathrm{C}$ with a mixing time of $1000 \mathrm{~ms}$. The measuring conditions for the 2D spectra were as follows: spectral width $4500 \mathrm{~Hz}$; data size $1024\left(F_{2}\right) / 486\left(F_{1}\right)$; relaxation delay $1.5 \mathrm{~s}$. Melting points were measured with a BÜCHI Melting Point B-545 and uncorrected. Optical rotations were recorded on a JASCO DIP-360 digital polarimeter. HRMS data were obtained using a Mariner spectrometer (PerSeptive Biosystems Inc.). MALDI-TOF-MS data were recorded using a JMS-S3000 spectrometer. Preparative TLC was performed on Merck silica gel 60GF254. Column chromatography was conducted using silica gel 60N (40-50 $\mu$ m, Kanto Chemical Co., Inc.) All anhydrous solvents were purified according to standard methods.

\subsubsection{3,7-Anhydro-3-C-benzyl-4,5,6,8-tetra-O-benzyl-2-deoxy-D-glycero-D-ido-octose (3)}

Ozone was bubbled through a solution of 2 (104.4 mg, $0.2 \mathrm{mmol})$ in $\mathrm{CH}_{2} \mathrm{Cl}_{2}(5 \mathrm{~mL})$ while stirring at $-78{ }^{\circ} \mathrm{C}$ for $10 \mathrm{~min}$. After triphenylphosphine (129.6 mg, $0.5 \mathrm{mmol}$ ) was added at $-78^{\circ} \mathrm{C}$, the reaction temperature was raised to room temperature and the reaction mixture was stirred for $2 \mathrm{~h}$. The solvent was then evaporated under reduced pressure. The crude product was purified by preparative TLC (hexane:ethyl acetate $=4: 1$ ) to afford 3 (99.8 mg,

97\%) as a colorless oil. $[\alpha]_{\mathrm{D}}^{23}=+22^{\circ}\left(c\right.$ 1.4, $\left.\mathrm{CHCl}_{3}\right) .{ }^{1} \mathrm{H}$ NMR $\left(600 \mathrm{MHz}, \mathrm{CDCl}_{3}\right): \delta 2.68(1 \mathrm{H}, \mathrm{dd}, J=2.5 \mathrm{~Hz}, J=$ $15.4 \mathrm{~Hz}, \mathrm{Ha} 2), 2.84$ (1H, dd, $J=3.7 \mathrm{~Hz}, J=15.4 \mathrm{~Hz}, \mathrm{Hb} 2), 3.01$ (1H, d, $J=14.2 \mathrm{~Hz}, \mathrm{Hb}$ ), 3.19 (1H, d, $J=14.1$ Hz, Ha9), 3.40 (1H, d, $J=9.5$ Hz, H4), 3.58 (1H, t, $J=9.6$ Hz, H6), 3.69 (2H, m, H6, Ha8), 3.74 (1H, dd, $J=3.4$ $\mathrm{Hz}, J=10.3 \mathrm{~Hz}, \mathrm{Hb} 8), 3.85$ (1H, t, $J=9.6 \mathrm{~Hz}, \mathrm{H} 5), 4.52-4.91$ (8H, m, CH $\left.\mathrm{C}_{2} \mathrm{Ph}\right), 9,62$ (1H, s, H1); ${ }^{13} \mathrm{C} \mathrm{NMR}(150$ MHz, $\mathrm{CDCl}_{3}$ ): $\delta 43.9$ (C-9), 44.5 (C-2), 69.1 (C-8), 72.8 (C-7), $75.0\left(\mathrm{CH}_{2} \mathrm{Ph}\right), 75.0\left(\mathrm{CH}_{2} \mathrm{Ph}\right), 75.6\left(\mathrm{CH}_{2} \mathrm{Ph}\right), 76.7$ ( $\mathrm{CH}_{2} \mathrm{Ph}$ ), 78.5 (C-6), 79.3 (C-3), 81.6 (C-4), 84.3 (C-5), 200.4 (C-1). HRMS (ESI): m/z calcd for $\mathrm{C}_{43} \mathrm{H}_{44} \mathrm{O}_{6} \bullet \mathrm{Na}^{+}:$ 679.3036; found 679.3045.

\subsubsection{3,7-Anhydro-3-C-benzyl-4,5,6,8-tetra-O-benzyl-2-deoxy-D-glycero-D-ido-octonic Acid} (4)

To a solution of $3(64.0 \mathrm{mg}, 0.1 \mathrm{mmol})$ in $t$-butanol $(3 \mathrm{~mL})$ and $\mathrm{H}_{2} \mathrm{O}(1 \mathrm{~mL})$ was added $\mathrm{NaClO}_{2}(38.2 \mathrm{mg}, 0.4$ mmol), $\mathrm{NaH}_{2} \mathrm{PO}_{4}$ (27.2 mg, $0.2 \mathrm{mmol}$ ), and 2-methyl-2-butene (46.4 $\left.\mu \mathrm{L}, 0.4 \mathrm{mmol}\right)$. After the reaction mixture was stirred for $24 \mathrm{~h}$, the reaction was quenched by adding $2 \mathrm{M} \mathrm{HCl}(1 \mathrm{~mL})$ and water $(5 \mathrm{~mL})$. After the reaction mixture was extracted with $\mathrm{CH}_{2} \mathrm{Cl}_{2}$ (three times), the combined organic solvent was dried over anhydrous $\mathrm{Na}_{2} \mathrm{SO}_{4}$. The organic solvent was filtered and evaporated under reduced pressure. The crude product was purified by preparative

TLC (hexane:ethyl acetate $=1: 1)$ to afford $4(64.2 \mathrm{mg}, 96 \%)$ as a colorless oil. $[\alpha]]^{23}=+34^{\circ}\left(c 1.2, \mathrm{CHCl}_{3}\right) .{ }^{1} \mathrm{H}$ NMR (600 MHz, $\mathrm{CDCl}_{3}$ ): $\delta 2.84(1 \mathrm{H}, \mathrm{d}, J=13.7 \mathrm{~Hz}, \mathrm{Ha} 2), 2.92$ (1H, d, $\left.J=16.4 \mathrm{~Hz}, \mathrm{Hb} 2\right), 3.01$ (1H, d, $J=15.1$ Hz, Hb9), 3.42 (1H, d, $J=15.1$ Hz, Ha9), 3.41 (1H, d, $J=6.8$ Hz, H4), 3.53 (1H, t, $J=9.6$ Hz, H6), 3.73-3.77 (2H,

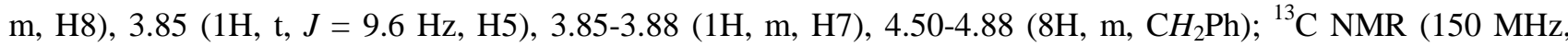
$\left.\mathrm{CDCl}_{3}\right): \delta 36.6$ (C-2), 42.5 (C-9), 69.0 (C-8), 72.9 (C-7), $73.2\left(\mathrm{CH}_{2} \mathrm{Ph}\right), 74.7\left(\mathrm{CH}_{2} \mathrm{Ph}\right), 75.0\left(\mathrm{CH}_{2} \mathrm{Ph}\right), 75.6\left(\mathrm{CH}{ }_{2} \mathrm{Ph}\right)$, 
78.4 (C-6), 79.3 (C-4), 80.1 (C-5), 84.1 (C-3), 175.1 (C-1). HRMS (ESI): $\mathrm{m} / \mathrm{z}$ calcd for $\mathrm{C}_{43} \mathrm{H}_{44} \mathrm{O}_{7} \bullet \mathrm{Na}^{+}$: 695.2985; found 695.3037.

\subsection{3. $6^{I}$-(3,7-Anhydro-3-C-benzyl-2-deoxy-D-glycero-D-ido-octonamido)-6 ${ }^{I}$-deoxycyclomalto} heptaose (1)

To a solution of 4 (45.2 mg, $0.07 \mathrm{mmol}$ ) in DMF (2 mL) was added dimethylphosphinothioyl chloride (8.6 mg, $0.06 \mathrm{mmol})$ and DIEA $(11.7 \mu \mathrm{L}, 0.07 \mathrm{mmol})$. After the reaction mixture was stirred for $40 \mathrm{~min}$, mono-6-amino-6-deoxy- $\beta$-CyD (85.2 mg, $0.08 \mathrm{mmol}$ ) in DMF $(1 \mathrm{~mL})$ was added. After the reaction mixture was stirred for $24 \mathrm{~h}$, the solvent was evaporated under reduced pressure. The resulting reaction mixture was washed with diethyl ether (eight times) and dissolved in DMF (15 mL). Palladium hydroxide (45.7 mg, $0.3 \mathrm{mmol}$ ) was added to the solution and hydrogen was bubbled through for $24 \mathrm{~h}$. After the solvent was filtered and evaporated under reduced pressure, the crude product was isolated by adsorption on HP 20 (DIAION), followed by elution

with methanol to afford 1 (55.2 mg, 58\%) as white crystals. Mp $\left.264-266{ }^{\circ} \mathrm{C} .[\alpha]\right]_{\mathrm{D}}^{23}=+126^{\circ}$ (c $\left.0.4, \mathrm{MeOH}\right) .{ }^{13} \mathrm{C}$ NMR (150 MHz, $\left.\mathrm{D}_{2} \mathrm{O}\right): \delta 12.8,22.8,36.2,41.3,43.2,43.2,55.0,60.6,60.6,60.8,62.7,71.2,71.7,72.4,72.6,72.6$, 72.8, 73.6, 73.8, 74.5, 74.6, 78.7, 80.1, 81.2, 81.3, 81.3, 81.6, 81.7, 84.3, 102.2, 102.5, 102.5, 102.6, 127.5, 128.0, 128.4, 128.8, 131.0, 136.4, 172.9. MALDI-TOF MS: $m / z$ calcd for $\mathrm{C}_{57} \mathrm{H}_{89} \mathrm{NO}_{40}{ }^{\circ} \mathrm{Na}^{+}: 1450.4859$; found. 1450.4899 .

\section{References and notes}

1. For example, (a) Jain, K.; Kesharwani, P.; Gupta, U.; Jain, N. K. Biomaterials 2012, 33, 4166-4186; (b) Ortiz M ellet, C.; Defaye, J.; García Fernández, J. M. Chem. Eur. J. 2002, 8, 1982-1990. Other references are cited therein.

2. (a) Yamanoi, T.; Yoshida, N.; Oda, Y.; Akaike, E.; Tsutsumida, M.; Kobayashi, N.; Osumi, K.; Yamamoto, K.; Fujita, K.; Takahashi, K.; Hattori, K. Bioorg. Med. Chem. Lett. 2005, 15, 1009-1013; (b) Yamanoi, T.; Kobayashi, N.; Takahashi, K.; Hattori, K. Lett. Drug Design Discovery 2006, 3, 188-191; (c) Oda, Y.; Kobayashi, N.; Yamanoi, T.; Katsuraya, K.; Takahashi, K.; Hattori, K. Med. Chem. 2008, 4, 244-255; (d) Oda, Y.; Yanagisawa, H.; Maruyama, M.; Hattori, K.; Yamanoi, T. Bioorg. Med. Chem. 2008, 16, 8830-8840; (e) Oda, Y.; Miura, M.; Hattori, K.; Yamanoi, T. Chem. Pharm. Bull. 2009, 57, 74-78.

3. It was reported that the CyD having the benzene unit also increase the association constants with Dox. (a) Swiech, O.; Mieczkowska, A.; Chmurski, K.; Bilewicz, R. J. Phys. Chem. B. 2012, 116, 1765-1771; (b) Swiech, O.; Dutkiewicz, P.; Wójciuk, K.; Chmurski, K.; Kruszewski, M.; Bilewicz, R. J. Phys. Chem. B. 2013, 117, 13444-13450.

4. (a) Yamanoi, T; Oda, Y. Heterocycles 2002, 57, 229-234. (b) Oda, Y.; Yamanoi, T. Synthesis 2007, 3021-3031.

5. Imata, H.; Kubota, K.; Hattori, K.; Aoyagi, M.; Jindoh, C. Polymer J. 1997, 29, 563-567. 
6. Our reported ranges of $k_{a}, k_{d}$, and $K_{a}$ values in other CyD conjugates having a benzene unit are as follows: $\mathrm{k}_{\mathrm{a}}=4 \times 10^{2} \sim 1.8 \times 10^{4} \mathrm{M}^{-1} \mathrm{~s}^{-1} ; \mathrm{k}_{\mathrm{d}}=3.8 \times 10^{-3} \sim 2.1 \times 10^{-2} \mathrm{~s}^{-1} ; \mathrm{K}_{\mathrm{a}}=1.1 \times 10^{5} \sim 5.3 \times 10^{6} \mathrm{M}^{-1}$. See ref. 2a-e.

7. (a) Yasuda, N.; Aoki, N.; Abe, H.; Hattori, K. Chem. Lett. 2000, 29, 706-707. (b) Husain, N.; Ndou, T. T.; Muñoz De La Peña, A.; Warner, I. M. Appl. Spectrosc. 1992, 46, 652-658.

8. Tanaka, H.; Nishida, Y.; Kobayashi, K. J. Carbohydr. Chem. 2000, 19, 413-418.

9. It is well known that the adjacent phenyl group generally stabilizes the coplanar conformation through hyperconjugate. For example, (a) Campanelli, A. R.; Ramondo, F. J. Phys. Chem. 1994, 98, 11046-11052. (b) An, Y.-P.; Yang, Z.; Ratner, M. A. J. Chem. Phys. 2011, 135, 044706.

10. For example, (a) Bekers, O.; Kettenes, J. J. V. D. B.; Helden, S. P. V.; Seijkens, D.; Beijnen, J. H.; Bulti, A.; Underberg, W. J. M. J. Incl. Phenom. Macrocycl. Chem. 1991, 11, 185-193. (b) Husain, N.; Ndou, T. T.; Peña, A. M. D. L.; Warner, I. M. Appl. Spectrosc., 1992, 46, 652-658. (c) A.-Omar, A.; Abdou, S.; Robertis, L. D.; Marsura, A. Bioorg. Med. Chem. Lett. 1999, 9, 1115-1120. 3a and 3b also provides the information. The $\pi-\pi$ parallel stacking interaction between the A ring of Dox and the aromatic phenyl ring strongly promotes due to effect of the electron deficiency of the A ring of Dox. See ref. 3a and $\mathbf{3 b}$. 